\title{
Erratum to: Theoretical reference values for the AE6 and BH6 test sets from explicitly correlated coupled-cluster theory
}

\author{
Robin Haunschild • Wim Klopper
}

Published online: 4 January 2013

(c) Springer-Verlag Berlin Heidelberg 2013

\section{Erratum to: Theor Chem Acc (2012) 131:1112 \\ DOI 10.1007/s00214-012-1112-3}

In the original publication of the article, some barrier heights for the reactions $\mathrm{H}+\mathrm{OH} \rightarrow \mathrm{O}+\mathrm{H}_{2}$ and $\mathrm{H}+\mathrm{H}_{2} \mathrm{~S} \rightarrow$ $\mathrm{H}_{2}+\mathrm{SH}$ and one atomization energy of the values reported are incorrect due to a small error which occured during addition of individual contributions. The correct atomization energy for $\mathrm{SiO}$ for FC-CCSD(T)/cc-pVQZ-F12 $+\delta_{\mathrm{HE}}+$ $\delta_{\mathrm{C} / \mathrm{CV}}$ is $801.7 \mathrm{~kJ} / \mathrm{mol}$. The affected levels of theory for the barrier heights are FC-CCSD(T)/cc-pV(Q+d)Z +
$\delta_{\mathrm{HE}}+\delta_{\mathrm{C} / \mathrm{CV}}$, FC-CCSD $(\mathrm{T}) / \mathrm{cc}-\mathrm{pV}(5+\mathrm{d}) \mathrm{Z}+\delta_{\mathrm{HE}}+\delta_{\mathrm{C} / \mathrm{CV}}$, $\mathrm{FC}-\mathrm{CCSD}(\mathrm{T}) / \mathrm{cc}-\mathrm{pV}(6+\mathrm{d}) \mathrm{Z}+\delta_{\mathrm{HE}}+\delta_{\mathrm{C} / \mathrm{CV}}, \quad$ and $\mathrm{FC}-\mathrm{CCSD}(\mathrm{T}) / \mathrm{CBS}+\delta_{\mathrm{HE}}+\delta_{\mathrm{C} / \mathrm{CV}}$. The correct values are given in Table 1.

After rectifying the errors mentioned, the values calculated on the FC-CCSD(T)(F12)/cc-pVQZ-F12 $+\delta_{\mathrm{HE}}+\delta_{\mathrm{C} / \mathrm{CV}}$ level of theory agree even better with the values on the FC-CCSD(T)/CBS $+\delta_{\mathrm{HE}}+\delta_{\mathrm{C} / \mathrm{CV}}$ level of theory.

None of these corrections affect the other tables nor the conclusion in the original article. The authors would like to thank Konstantinos Vogiatzis for making them aware of these errors.
Table 1 (revised part of Table 2) Barrier heights for the reactions of the BH6 test set in $\mathrm{kJ} / \mathrm{mol}$

\begin{tabular}{|c|c|c|c|c|}
\hline & \multicolumn{2}{|c|}{$\mathrm{H}+\mathrm{OH} \rightarrow \mathrm{O}+\mathrm{H}_{2}$} & \multicolumn{2}{|c|}{$\mathrm{H}+\mathrm{H}_{2} \mathrm{~S} \rightarrow \mathrm{H}_{2}+\mathrm{SH}$} \\
\hline & $\overline{E_{\mathrm{fwd}}} \neq$ & $E_{\mathrm{rev}}^{\neq}$ & $\overline{E_{\mathrm{fwd}}} \neq$ & $E_{\mathrm{rev}}^{\neq}$ \\
\hline $\mathrm{FC}-\mathrm{CCSD}(\mathrm{T}) / \mathrm{cc}-\mathrm{pV}(\mathrm{Q}+\mathrm{d}) \mathrm{Z}+\delta_{\mathrm{HE}}+\delta_{\mathrm{C} / \mathrm{CV}}$ & 44.4 & 58.0 & 16.6 & 73.6 \\
\hline $\mathrm{FC}-\mathrm{CCSD}(\mathrm{T}) / \mathrm{cc}-\mathrm{pV}(5+\mathrm{d}) \mathrm{Z}+\delta_{\mathrm{HE}}+\delta_{\mathrm{C} / \mathrm{CV}}$ & 44.9 & 55.7 & 16.2 & 72.2 \\
\hline $\mathrm{FC}-\mathrm{CCSD}(\mathrm{T}) / \mathrm{cc}-\mathrm{pV}(6+\mathrm{d}) \mathrm{Z}+\delta_{\mathrm{HE}}+\delta_{\mathrm{C} / \mathrm{CV}}$ & 45.0 & 55.0 & 16.0 & 71.7 \\
\hline $\mathrm{FC}-\mathrm{CCSD}(\mathrm{T}) / \mathrm{CBS}+\delta_{\mathrm{HE}}+\delta_{\mathrm{C} / \mathrm{CV}}$ & 45.1 & 53.9 & 15.8 & 71.0 \\
\hline
\end{tabular}

The online version of the original article can be found under doi: 10.1007/s00214-012-1112-3.

\footnotetext{
R. Haunschild ( $\square) \cdot$ W. Klopper

Theoretical Chemistry Group, Institute of Physical Chemistry,

Karlsruhe Institute of Technology, KIT Campus South,

Fritz-Haber-Weg 2, 76131 Karlsruhe, Germany

e-mail: haunschild@kit.edu

W. Klopper

e-mail: klopper@kit.edu
} 